\title{
Itinerância dos artistas: a construção do campo das artes visuais em Brasília 1958-2008
}

\author{
Tálisson Melo
}

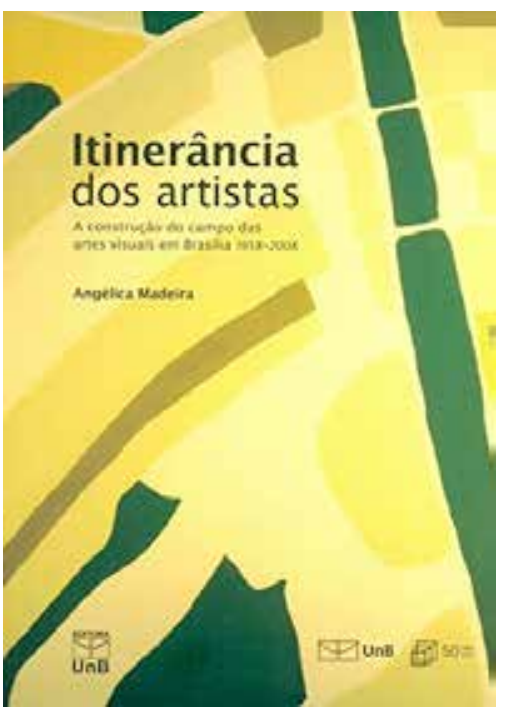

O livro "Itinerância dos artistas: a construção do campo das artes visuais em Brasília 1958-2008", escrito pela pesquisadora Angélica Madeira, constitui-se de seis ensaios relativamente independentes que, em conjunto, apresentam os caminhos de um estudo sobre o campo artístico na capital federal do Brasil2. De caráter ensaístico, abre espaço para apontamentos metodológicos da autora que permitem o leitor acompanhar e apreender que esta leitura se costura em rede, entre arquivos, referências bibliográficas, entrevistas, teorias, questionamentos e escolhas de procedimento e abordagem, deixando claro que o que se lê segue por uma trilha dentre outras possíveis.

Madeira lança mão do conceito de "itinerância" como central para sua reflexão acerca das ideias, pessoas e objetos que aborda. A cidade de 
Brasília faz-se presente ora como objeto, ora como ponto de articulação desses elementos - espaço geográfico, imaginado ou vivido, projetado ou experienciado, controlado ou desviante, para onde a trajetória sempre volta, alternadamente às viagens entre o eixo Rio de Janeiro e São Paulo, outras cidades do Brasil e outros cantos do mundo. A itinerância dá-se também nesta dimensão da leitura, no tempo e no espaço.

Também é itinerante o olhar da autora, passeia pelas exposições, arquivos e catálogos com teorias na bagagem. História, sociologia, antropologia e filosofia são concatenadas para orientar o percurso entre instituições (do campo cultural, econômico e político), atores (artistas, críticos, professores, historiadores, curadores e jornalistas) e algumas obras de arte específicas sobre as quais deteve o olhar.

Chama atenção o movimento de convergência, aparece desde a introdução do livro e segue norteando todo o movimento de leitura da pesquisa realizada. Não se trata somente do fato de Brasília caracterizar-se como ponto de encontro, troca de ideias, objetos, práticas e valores culturais entre artistas e intelectuais de todas as regiões do país, mas também pelo diálogo entre estética e política, lugar e trajetória, posição geográfica e existencial.

Em "uma cidade em que o campo das artes se movia tão próximo às vicissitudes políticas e institucionais" (MADEIRA, 2013, p. 186), a arte e a política são consideradas sempre em relação (negociação e tensão).

Inicialmente, é revelado o interesse da pesquisa: compreender de que forma a cidade interpela a criação artística - "a cidade como centro de debates de ideias, lugar dos intelectuais e dos artistas" (p. 15). Ainda na introdução, a autora aponta para as perguntas mais específicas que surgiam a partir do aprofundamento de sua relação com as fontes e a ampliação desses referencias. No desenvolvimento de cada um dos capítulos seguintes o texto é desenhado de modo a evidenciar a complexificação do recorte, Brasília torna-se um mundo, para além de sua representação.

À medida que se apresentam novas informações, relações, similaridades e especificidades do objeto, são evocadas diferentes teorias auxiliares de análise, e o traçado metodológico da pesquisa é articulado ao longo do texto de maneira transparente e clara; o que se mostra 
especialmente válido para pesquisadores em formação no campo da história, sociologia e antropologia da arte. A construção do pensamento, a relação com o material levantado e o processo de um trabalho duro e ao mesmo tempo criativo de estabelecer questões e direcionar-se a respondêlas, mobilizando um vasto repertório de ideias, configura-se como uma grande contribuição deste livro. Além, é claro, de trazer para o debate sobre as artes visuais no Brasil, os desdobramentos de suas práticas em outro contexto, deslocado das cidades do Rio de Janeiro e São Paulo, sem, contudo, negar sua relação com esse "eixo".

No primeiro capítulo, A cidade e as artes: 1958-1967, Madeira persegue as itinerâncias que levaram à construção da atual capital federal, através das estradas de ideias e interesses do campo político e econômico nacional que convergem com as propostas estéticas modernas, para dar corpo a um projeto coletivo.

São abordados, de maneira integrada, aspectos marcantes da história brasileira na década de 1950: o surto de desenvolvimento que acompanhou o processo de industrialização e urbanização, e a consolidação de um campo institucionalizado para a arte moderna - com museus erguidos nas maiores cidades do país ainda nos 1940, a Bienal de São Paulo em 1951, e o debate em torno do Concretismo brasileiro.

O ano de 1958, com a transferência da equipe de arquitetura da Novacap para o local eleito onde se construiria a cidade, pontua o início de um processo paralelo de concepção, construção e debate acerca de Brasília. A pesquisadora traz para esse contexto as ideias elaboradas por críticos de arte de distintas cidades e países que se encontraram na realização, no ano seguinte, de um Congresso Extraordinário da Associação Internacional de Críticos de Arte, com o tema "A Cidade Nova - Síntese das Artes".

Aqui, o elemento de convergência entre arte e política reside na arquitetura e no urbanismo (as artes visuais integradas nestes ambientes), para compor o emblema da modernização brasileira, contando com o envolvimento da sociedade e o movimento de milhares de pessoas de diversos cantos do país, desde operários para as obras a artistas e intelectuais para a formação do corpo docente do Instituto de Comunicação e Artes (ICA) da Universidade de Brasília. 
Nas palavras do crítico brasileiro Mário Pedrosa (1901-1981) - figura cara à pesquisa, a quem será dedicado um dos próximos capítulos desse livro - é-nos apresentada uma síntese da composição da cidade: "[...] se a ideia de Brasília é construtiva, muito do que existe nela é barroco. [...] sua monumentalidade, suas contradições e conflitos, seu aspecto cenográfico, suas perspectivas erradias, fugas e contrafugas, certo clima de fausto e exuberância" (PEDROSA, 1981, apud MADEIRA, 2013, p. 40).

A concepção híbrida para uma vida estetizada, a forte presença dos arquitetos brasileiros, Lúcio Costa (1902-1998) e Oscar Niemeyer (19072012), em sua gestação, produzindo os prédios sede da burocracia estatal, palácios, espaços verdes, blocos residenciais, o Congresso, os ministérios, a Catedral, "modulações e vazios" de sua paisagem: "a sensibilidade moderna dos anos 1950 estabeleceu Brasília como parâmetro de sua própria utopia" (MADEIRA, 2013, p. 38).

patrocínio estatal às artes e sua função pedagógica (estética e cívica), fundação de seu simbolismo em escala grandiosa, também é enfocado pela autora: como exposições de arte em galerias de prédios públicos e saguões de hotéis de 1959, "imprescindiveis para a cidade legitimar-se como capital" (MADEIRA, 2013), e os Salões de Arte Moderna "para a dinamização do campo das artes", diante dos quais foi possível reconhecer um grande embate entre "a vanguarda de uma arte cada vez mais universal [...] e o polo de uma arte deliberadamente regional, numa insopitável vontade de afirmação dialetal ou nacional." (PEDROSA, 1981, apud MADEIRA, 2013, p. 57).

A arte pública é vista como "mecanismo de identificação", a abstração moderna de murais, esculturas e pinturas atestava a ligação da cidade com as vanguardas artísticas, ao mesmo tempo em que a figuração oficial (fundição de efígies, bustos e esculturas naturalistas), fornecia os elementos de conexão histórico, civil e religiosa.

No quadro de dez anos abordado no capítulo, 1964 é quando se provoca uma descontinuidade. Consequentemente ao golpe militar, o campus da UnB foi ocupado por tropas do exército e da polícia militar, treze professores e um estudante foram demitidos, sem acusação formal ou processo, levando a um movimento de dispensas e demissões voluntárias 
que causou um desfalque no corpo docente da instituição no ano seguinte. Situação que demandou recrutamento de artistas da antiga capital e outras partes do Brasil.

O recrudescimento da repressão a partir do Ato Institucional de número 5, em 1968, encerra essa sessão de análise da primeira década na cidade. Duas trajetórias são colocadas em paralelo para elucidar o momento que a autora chama de uma "utopia construtiva": a obra dos artistas Athos Bulcão (1918-2008) e Rubem Valentim (1922-1991). Os murais e azulejos de Bulcão para o Brasília Palace Hotel, para a igreja de Nossa Senhora De Fátima (projetada por Niemeyer), para um cinema, teatro, torre de televisão, o Palácio dos Arcos e o Itamaraty - síntese entre a tradição moçárabe e a modernidade construtiva. A produção do baiano Valentim, que chegou a compor o corpo docente do ICA, trouxe a síntese entre arte popular e construtiva.

O segundo capítulo, "Arte e política no contexto autoritário", aborda o período posterior ao golpe que instaurou o regime militar no país, num arco histórico que alcança até o final da década de 1970, compreendendo a primeira geração de artistas formados na capital federal. Brasília é apresentada então como uma "cidade quartel", dentro da qual o campo artístico e o campo político se chocavam.

O regime convivia, não sem conflito, com a emergência da contracultura e da "arte de revolta" - na poesia, teatro, música e artes visuais - com suas "expressões desconcertantes e sujas":

[...] tornou-se polo irradiador de tendências nas artes visuais, música e poesia, onde propostas radicais emergiam burlando o severo controle estabelecido pelo regime militar, surpreendendo com suas poéticas contestatórias e marginais. (MADEIRA, 2013, p. 60)

Madeira aborda as condições de possibilidade para a produção de "enunciados estéticos", circunscrita contaminada pela configuração histórica e política. Nessa análise permanece o diálogo com alguns textos de Mário Pedrosa sobre a produção artística dos anos de 1960 e 1970 que via "inaugurado um novo ciclo nas artes" -, e somam-se outros autores 
extremamente relevantes ao debate à época - nomeadamente os filósofos franceses Gilles Deleuze (1925-1995), Félix Guatarri (1930-1992) e Michel Foucault (1926-1984).

Os "Parangolés" de Hélio Oiticica (1937-1980) podem ser tomados como abre-alas de uma série de experimentações artísticas que emergiram no período, pois aponta para caminhos de ruptura nos quais tais produções instalar-se-iam: a antiarte (questionando os valores consensuais do campo) e a "arte engajada" ("microrrevoluções individuais e cotidianas", "inserções em circuitos ideológicos"). A rebeldia das propostas de uma jovem geração que reorienta o campo artístico nacional.

Pelo Brasil, exposições como "Opinião 65", "Nova Objetividade Brasileira" e "Salão da Bússola" (no Museu de Arte Moderna do Rio de Janeiro, em 1965, 1967 e 1969, respectivamente), "Proposta 65" e "Proposta 66" (na Fundação Armando Álvares Penteado, em São Paulo, 1965 e 1966), a II Bienal da Bahia (em Salvador, 1968) e "Do Corpo à Terra" (no Parque Municipal de Belo Horizonte, em 1970). Enquanto em Brasília, foi o $4^{\circ}$ Salão de Artes Plásticas, em 1967, que marcou o rumo do debate no momento. A polêmica gerada entre os membros do júri a partir da obra inscrita pelo artista paulista Nelson Leirner, "Porco Empalhado". Os ready-made de Marcel Duchamp (1887-1968) foram evocados e reinseridos na discussão e no repertório de referência desses artistas - convergem as referências ao dada, pop art, arte conceitual intervenção política e crítica institucional.

O ambiente da capital não se encontrava favorável à profissionalização dos artistas, que recorriam às cidades cujo campo artístico estivesse mais consolidado (em geral, Rio de Janeiro e São Paulo). Contudo, diante do cenário de repressão, censura e precariedade chegava a circular informação atualizada na capital interiorizada, muito devido às itinerâncias dos artistas e críticos, contribuindo para a manutenção de um grupo de artistas locais, conhecidos como o "Grupo de Brasília" (composto por Cildo Meireles, Guilherme Vaz, Alfredo Fontes, Luis Alphonsus, entre outros).

A trajetória de Cildo Meireles é destaca ao fim do capítulo, suas "Inserções" conectavam os elementos de transgressão, resistência e marginalidade da arte conceitual emergente, e a cidade de Brasília, onde viveu sua adolescência, foi tomada como espaço de circuitos ideológicos 
e ao mesmo representação (em mapas) para sua instalação/ritual intitulada "Caixa Brasília", exibida durante o "Salão da Bússola" no MAM do Rio, em 1969.

A virada para a década de 1980 é marcada pela intensificação da globalização da arte contemporânea e ampliação de seu mercado, "tanto Cildo Meireles quanto Nelson Leirner atravessaram a fronteira que separa espaço de transgressão e cooptação pelo mercado" (MADEIRA, 2013, p. 104).

As referências ao crítico Mário Pedrosa são aprofundadas e estendidas no capítulo três. Sua ligação com Brasília foi ativa e anterior a sua inauguração, participou da organização de eventos e exposições, como o já mencionado Congresso da AICA. Em sua trajetória (ou "itinerância", como referida pela autora), convergiam a militância política e mediação crítica da produção artística, entre a estética e a política.

A capital, enquanto projeto urbanístico e arquitetônico, emblema da nova sensibilidade moderna, "ensaio de utopia", teve em Pedrosa um defensor e entusiasta. Porém, diante da imagem que se configura e das contradições inerentes de um "festim de arte" patrocinado pelo Estado, ele também apontou suas falhas em textos mais tardios.

Esse capítulo, por tecer uma rede de visões sobre Brasília, o Brasil e as artes a partir das ideias um intelectual específico, torna-se particularmente interessante no sentido em que situa-o como fonte de repertório para a análise que a pesquisadora estabelece sobre o campo artístico brasiliense e nacional à época. A obra crítica de Pedrosa é tomada como documento histórico e ao mesmo tempo como construtora de perspectiva, ressoa o conjunto de ensaios que compõe o livro e confere-lhe mais coerência.

O caráter utópico que é evidenciado na referência enfática ao crítico de arte e militante político norteia a apreensão das décadas mais próximas do contexto histórico de elaboração da pesquisa. Intitulado Anos 1980 e depois: o fim das utopias, o quarto capítulo traça de maneira mais ampla as transformações no contexto histórico e social: sociedade de consumo, neoliberalismo e globalização são as noções que emolduram a apreensão da mudança nas condições de produção artística, na posição do artista e suas formas de inserção. 
No Brasil, esse período marcou o processo de democratização e mudanças decorrentes da volta ao estado de direito:

[...] a arte vem se misturar a causas e, para o bem e para o mal, culturaliza-se, sociologiza-se, cientifiza-se, envolvese em processos comunitários, torna-se mais emocional, às vezes com grande inteligência e criatividade, às vezes com grande prejuízo e criatividade, às vezes com grande prejuízo para a própria arte, derivando em esoterismo ou filantropia (MADEIRA, 2013, p. 138)

Categorias e valores tradicionais passam a ser constantemente questionados pelos artistas, como o belo e o puro, enquanto outras categorias consagram-se, como o abjeto, fragmentário, híbrido e grotesco. A arte é dessacralizada, vista como uma esfera social entre outras, "constitutiva do real". Os artistas trilham suas itinerâncias entre a academia, museus, bienais, fundações, feiras e galerias. Suas obras, muitas vezes, são elaboradas como respostas aos impasses de sua nova posição, lidando com as temáticas da subjetividade, do mercado e da mídia.

A profissionalização e especialização de práticas de mediação (jornalismo cultural, teoria, crítica, curadoria e capitação de recursos), interpõem-se em um contexto de privatizações na esfera cultural. Sem a imposição do ethos coletivo que guiava os movimentos de vanguardas históricas, agora os artistas se agrupam sem deixar de formular suas estratégias de ação individuais: "compreendem o fazer artístico como uma intervenção no mundo real" (p. 138).

Suas incursões em movimentos de afirmação identitária, o feminismo, embates políticos e sociais, "diálogos com tradições perdidas", mobilização de diferentes meios e tecnologias novos. A pesquisadora identifica o que chama de uma "tendência neobarroca" vigorosa a partir dos 1980:

Alguma coisa de muito importante havia ocorrido entre uma geração e a outra, ou entre a década de 1970 e a de 1980. Até meados dos anos 1970, acreditava-se que se podia fazer frente à indústria cultural e à sociedade de consumo e estabelecer formas alternativas de estilo de vida, criar outros valores. Já nos anos 1980, essa 
ilusão está superada e participar de um sistema cultural midiático passou a ser o ideal dos que se dedicam à produção de bens culturais, sem nenhum resquício da reticência demonstrada pela geração anterior ao mercado e à indústria cultural. (MADEIRA, 2013, p. 145)

Em Brasília, graças à ampliação do acesso ao diálogo e acervo da cultura universal, artistas formam o corpo de sua obra em contato direto com as questões acima referidas. Madeira analisa obras pontuais de alguns artistas brasileiros atuantes à época, sendo particularmente estimulantes as relações que estabelece com a produção artística na capital federal - como o trabalho de Andrea Farias, Gladstone Machado de Menezes e Nilce Eiko Honashiro.

O repertório que emerge dessas itinerâncias mais atuais, entre instalações, performances, obras conceituais e intervenções, é tratado de modo mais estendido no capítulo seguinte, Arte contemporânea: tendências fragmentárias. Contaminações entre pintura, escultura, fotografia, design e estratégias publicitárias; história da arte, antropologia, filosofia, biologia e política; subjetividade, coletividade e natureza; high e low tech.

Brasília hoje "é tão complexa quanto qualquer centro urbano" e os artistas que fazem dela um ponto em sua trajetória podem circular por campo artístico mais bem aparelhado, com instituições de ensino, pesquisa e divulgação de sua obra. A cidade planejada que cresceu e desafiou os limites de sua concepção, apresenta em si maior diversidade e densidade da vida cultural, contribuindo para a projeção de um contingente significativamente plural, embora continue "carente de equipamentos e políticas culturais duradouras e efetivas" (MADEIRA, 2013, p. 186). Convivem três gerações de artistas e instituições (a utópica, a politicamente engajada, e a da democratização). Para a geração atual, a convergência entre as dimensões estéticas e políticas é vigorosa e marca o itinerário desses artistas, cujo status depende de meios de legitimação e consagração mais numerosos de uma rede de atores especializados - os mediadores.

Diante da inviabilidade de abranger todas as itinerâncias singulares de artistas e suas obras para desenhar um mapa, a pesquisadora adota 
outro procedimento: passa a focar propostas poéticas específicas em determinadas exposições que tiveram lugar em Brasília, exibindo a produção "local", e buscar regularidades, comunidades de interesse e parentescos artísticos, identificar a informação cultural compartilhada, os vínculos criados entre artistas, grupos e coletivos brasilienses. Determinadas galerias, como a Espaço Capital nos anos 1980 ou a Arte Futura no 2000, os editais para galerias, projetos e bolsas lançados pela Fundação Nacional de Arte (Funarte) desde final dos 1970, cursos promovidos pelo Sesc e o Sesi com cursos, o programa Rumos Visuais desenvolvido pelo Instituto Cultural Itaú a partir dos 1990, entre outras iniciativas, figuram como plataformas de projeção de novos artistas, uma teia composta por itinerâncias diversas.

Obras pontuais de artistas conectados à cidade são analisadas pela autora com maior detenção. Aparecem nomes que acompanham produções muito diversas, como Júlio César Lopes, Stella Maris Bertinazzo e Glênio Lima. São destacadas também as formações de grupos e coletivos, como o Corpos informáticos, atuante desde 1992, e outros estabelecidos ao longo da última década, como o projeto Entorno desde 2002, Brasília Faz Bem de 2004, o Fora do Eixo que surgiu em 2006, realizando intervenções urbanas, performances e intercâmbios entre artistas.

Madeira aponta a persistência da concepção moderna sobre a função primordial da arte entre os insiders: "despertar os homens de sua letargia, isto é, de seu comodismo midiático e do consenso plano do dia a dia" ( $p$. 223). Evidência ainda outro aspecto importante que reside na consciência sociológica sobre o funcionamento do campo, marcado por cooperação e disputas

O último capítulo, Arquivistas, cronistas, artistas: a fotografia em Brasília, pode ser compreendido como um exercício metodológico de retomar todos o arco histórico de meio século oferecido pela nova capital do país, tento a imagem fotográfica como mote da releitura.

A primeira foto, espécie de documento visual da expedição Cruls de 1892, onde o local de construção da cidade grafa-se por primeira vez, parece isolada; depois de pouco mais de cinquenta anos reaparece em fotografias da década de 1950 e 1960, dedicadas ao registro do processo de construção de Brasília, sua arquitetura, os primeiros imigrantes e seu 
cotidiano. São os fotógrafos arquivistas, documentando a corporificação de um plano.

A produção fotográfica das décadas de 1970 e 1980, de acordo com a leitura da autora, é elaborada por fotógrafos cronistas: o vínculo da imagem fotográfica com seu papel social ativo, os registro e visibilidade de excluídos e do dia a dia do poder. Aproximadamente a partir dos anos de 1990, os fotógrafos se estabelecem como artistas e levam sua produção para o terreno do conceitualismo, dialogando com a tradição visual disponível, preocupados com suas camadas poéticas e subjetivas, contatos com as manifestações da cidadania e democracia.

Diante das relações entre a fotografia e a cidade ("hiperfotografada"), Angélica Madeira consegue evidenciar a convergência entre estética e política que identifico como movimento principal deste conjunto de ensaios. Esse encontro de noções permite compreender o modo como se organiza o campo das artes visuais em Brasília nos diferentes momentos da construção e legitimação da cidade-capital. Sua leitura revela-se como um exercício profícuo e aberto para pensar o campo artístico em sua relação com outros campos.

Recebido em 11/05/2016

Aprovado em 20/12/2016 